\title{
10. Survey suggests rising risk of food and nutrition insecurity in Addis Ababa, Ethiopia, as COVID-19 restrictions continue
}

\author{
Kalle Hirvonen, Gashaw Tadesse Abate, and Alan de Brauw
}

As the COVID-19 pandemic has spread to virtually every corner of the world, lockdowns, supply disruptions, and economic pain have followed in its wake, raising alarm about food and nutrition security among policymakers, the development community, and other observers. Representative survey data on households' immediate and longer-term responses to the pandemic are necessary to understand these impacts and their implications, and to plan and target appropriate responses. The need is especially urgent for urban areas, where residents may face greater public health risks and tighter restrictions.

To cast light on how households in Addis Ababa, Ethiopia, are reacting to the crisis, IFPRI's Ethiopia Strategy Support Program (ESSP), with the support of the CGIAR Research Program on Agriculture for Nutrition and Health (A4NH), has begun a series of monthly phone surveys. Initial data demonstrate that poorer households are taking a greater economic hit than those with higher incomes, and that dietary diversity has declined. The results suggest the food security situation in Addis Ababa could sharply deteriorate in the coming weeks if disease transmission and social distancing measures continue.

The phone surveys build on data collected from a representative sample of households that participated in a randomized controlled trial in 2019, with the endline taking place in early 2020 . The first phone survey was conducted in early May and covered 600 households, as will subsequent rounds, with an emphasis on ensuring household respondents are spread across the Addis Ababa income distribution.

Ethiopia confirmed its first COVID-19 case on March 13. The Ministry of Health immediately began contact tracing and isolating those who tested positive for the virus. Three days later, the government closed schools, banned all public gatherings and sporting activities, and recommended social distancing. Other measures to prevent the spread of the virus soon followed. Travelers from abroad were put into a 14-day mandatory quarantine, bars were closed until further notice, and travel across land borders was prohibited. Several regional governments imposed restrictions on public transportation and other vehicle movement between cities and rural areas.

While the policies were clear, as in many other countries there was confusion, mixed implementation, and a range of economic fallout. Our initial phone survey, conducted between May 1 and May 6, 2020, aimed to capture the immediate effects on people and their knowledge of the disease. It shows 


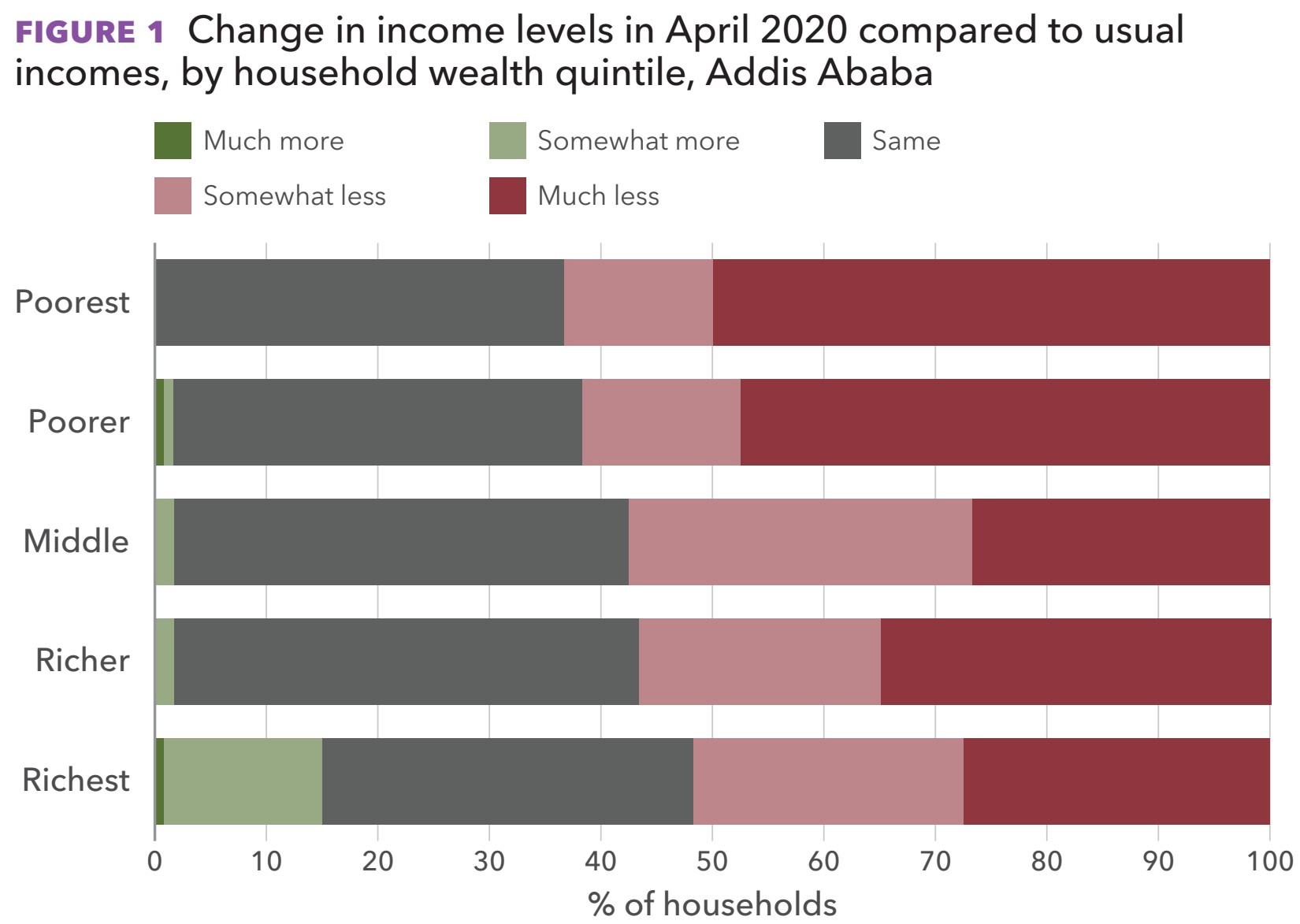

$\mathrm{N}=600$ households

Source: Authors' calculations from Addis Ababa COVID-19 phone surveys.

that almost all households are aware of COVID-19, and most are aware of basic preventative measures such as hand-washing and social distancing. Like many people in developed countries, a relatively large share of the sample - 35\% - stated that they are "extremely stressed."

We asked respondents to compare their household income in April 2020 to their usual household income at this time of year (Figure 1). About 37\% of respondents stated their households had "much less income" and another $21 \%$ stated their households had "somewhat less income." When we examine reported losses by wealth quintile (defined using the survey conducted in January and February), we find poorer households are much more likely to report much less income during April than richer households.

How are households dealing with reduced incomes? We asked those who reported income losses to share their primary strategy, and we find that about two-fifths report using savings, and another one-fourth report reducing their household food expenditures. Households do not report having much savings on average; about two-fifths have only enough savings for up to 14 days of food expenditures, and only $10 \%$ of all households report having enough savings for more than a month of food expenditures. 


\section{FIGURE 2 Changes in household reports of consumption of specific foods between February and April 2020, Addis Ababa}

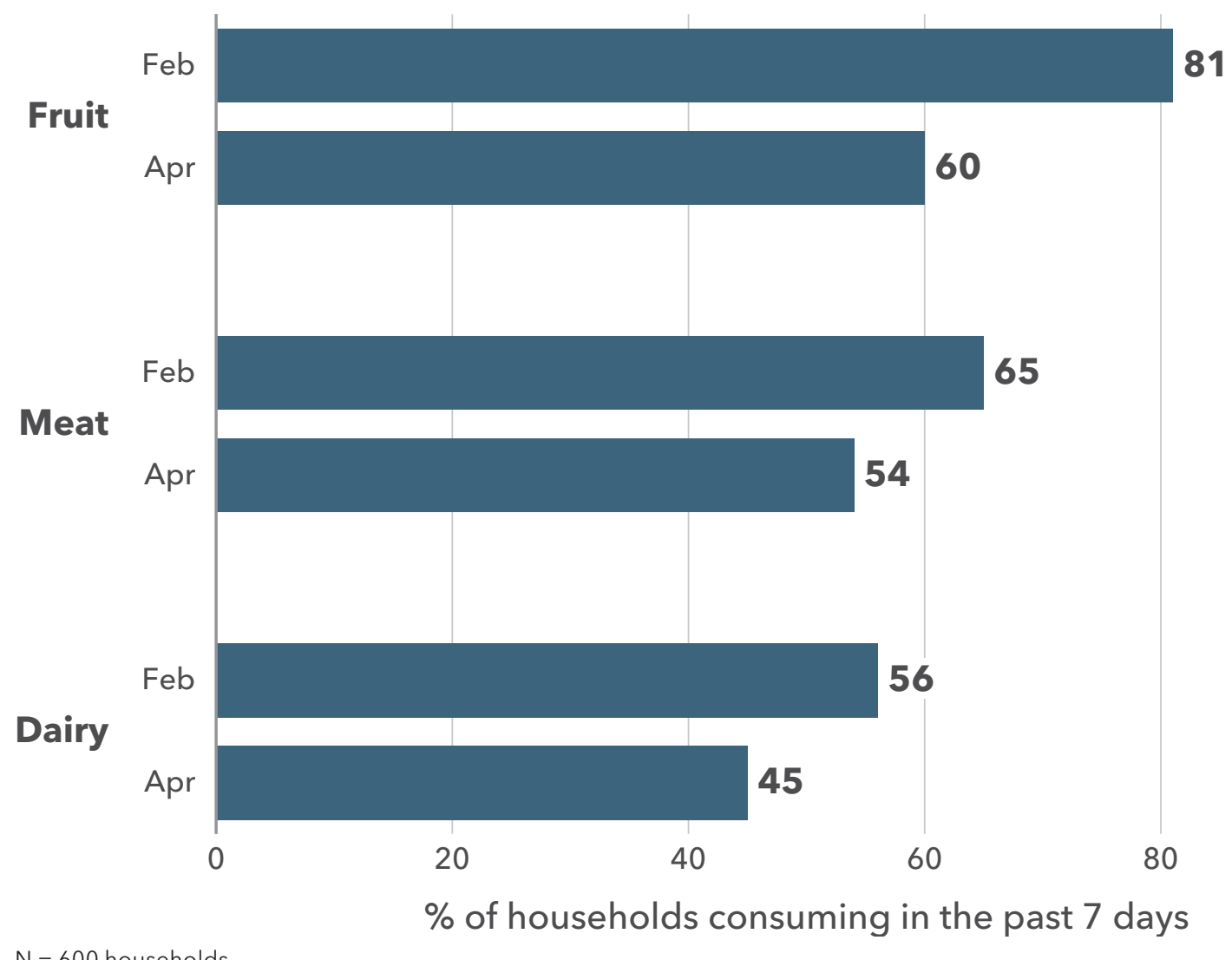

$\mathrm{N}=600$ households

Source: Authors' calculations from Addis Ababa COVID-19 phone surveys.

With declining food expenditures, we observe diet changes already beginning to occur. We administered a standard household dietary diversity score module, repeated from the (in-person) survey in early 2020. We find households are less likely to report consuming fruits (declining from $81 \%$ to $60 \%$ of households), meat (65\% to 54\%), and dairy (56\% to 45\%) (Figure 2). These results suggest concerns about the declining nutrient density of diets are real: households are reducing food expenditures by substituting away from more nutrient-dense foods to cheaper, less-nutrient-dense foods. These results are worrisome, as there is substantial uncertainty about how long the pandemic and its economic impacts will persist, and in the long term such dietary changes could both increase malnutrition and be detrimental to the food system as a whole.

A major disruption like a pandemic has serious implications for the evolution of food systems. When negative shocks occur, food purchase decisions can shift from a focus on dietary diversity toward ensuring there is enough to eat. Our data show that many households in Addis Ababa have done just that, though their overall food security status is not yet alarming. However, as personal savings dwindle, the likelihood that we will observe a rapid increase in food insecurity in the near future is quite high if COVID-19 restrictions continue. 
While these measures limit the spread of COVID-19, they come at a high cost, particularly to the poorest households. One policy response would be to rapidly scale up existing support programs before the food insecurity and hunger situation reaches alarming levels. In urban Ethiopia, the Urban Productive Safety Net already provides an established framework for identifying the poorest and most affected households. Another important response is to support the 1,000 food banks that have been established in Addis Ababa to curb the likely deterioration in food security. Only concerted assistance can help to sustain a population cut off from its income and facing fewer, and worse, food choices as a result. In further survey rounds, we plan to continue tracking both how policies reach sample households and how food and nutrition security change among these households.

Originally published May 21, 2020. 